\title{
Design Procedures and Analysis for Single-Phase Variable Reluctance Motors
}

\author{
A. C. F. Mamede ${ }^{1}$, J. R. Camacho ${ }^{1}$, D. A. Andrade ${ }^{2}$
}

${ }^{1}$ School of Electrical Engineering

Universidade Federal de Uberlandia (UFU)

Campus Santa Mônica - Av. João Naves de Ávila, 2121. Postcode: 38400-902 - Uberlandia (Brazil)

Phone:+55 343239 4734, e-mail: anacamilamamede@gmail.com, jrcamacho@ufu.br, darizon@ufu.br

\begin{abstract}
Variable reluctance motors have been increasingly used as an alternative for variable speed drives in many industrial applications, due to many advantages like it's construction simplicity, robustness, and low cost. For low power applications, the single-phase variable reluctance motors stands out because the simplicity of the drive contributes to the cost reduction of the machine. This paper presents a design methodology for single-phase variable reluctance motors and a way to survey of ideal profiles of inductance and torque produced by the motor through computational simulation using finite element methods. The simulation is performed for various currents in order to determine the maximum motor operating current through the analysis from the saturation of magnetic materials. In addition, an analysis is made on the influence and importance of rotor and stator polar arcs in the design of reluctance motors based on its driving system. The prototype has been designed to replace a single-phase induction motor with $0.18 \mathrm{~kW}$ and has four poles on stator and rotor, the nominal power is $0.125 \mathrm{~kW}$ and can deliver up $0.30 \mathrm{~kW}$ when operated with the maximum allowed current.
\end{abstract}

Keywords - Variable reluctance motors, finite-element method, design procedure, inductances, magnetic saturation.

\section{Introduction}

The use of a Variable Reluctance Motor (VRM) in industrial applications has increased considerably, especially in variable speed applications, it happened due to the technological development of systems and devices that allowed an efficient control, enabling the use of VRM rather than other electric machines.

The VRM are robust, reliable, has simple and cheap construction, making them ideal for electric traction applications and other solutions like drives, ventilation, pumps, high-speed applications. Its main disadvantages are the discontinuous torque and torque ripple, which can cause audible noise and vibration [2].

The VRM is a doubly salient motor that consists of a fixed part, the stator with excitation windings and a movable part, the magnetic rotor. The torque is produced solely by the tendency of its movable part to move to the position in which the inductance of the exciting winding is maximized, that is, the motor poles. The rotating part, the rotor, tends to align itself in order to produce a minimum reluctance and thus the maximum flux density [2].

Figure 1 shows the drawing of radial cut in two dimensions of a single-phase VRM with four stator poles and four poles in the rotor, this configuration is often referred to as 4:4 VRM. Figure 2 shows the ideal inductance profile, the current and ideal torque produced by a motor with this configuration.

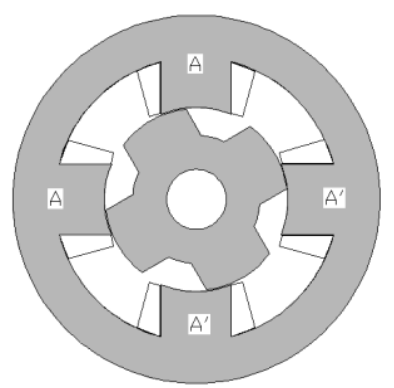

Fig. 1. Cross section of a single-phase 4:4 VRM.
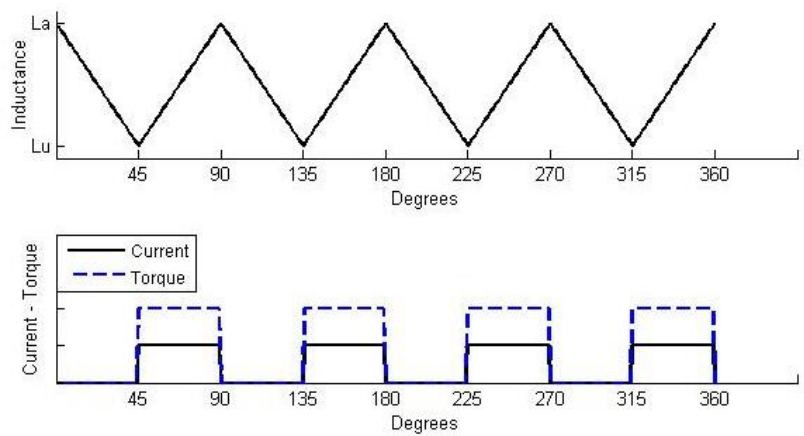

Fig. 2. Inductance profile and positive torque generation in a 4:4 VRM.

The single-phase VRM is a particular type of VRM in which the number of phases is reduced to unity and the number of poles on the stator and rotor are equal, the constructive characteristics are similar to other VRM, but control of this motor is much simpler since it is necessary to control only one phase.

The motor analysis by finite element methods allows, from a computer simulation, to know the engine behaviour before building a prototype. Thus, the designer can get the motor parameters with satisfactory accuracy and use them to optimize the design, and specify the drive for a given application.

Section 2 of this paper presents a study on the influence of the dimensions of polar arcs in motor design. The design procedure for a single-phase VRM, with 4:4 configuration, design was shown in Section 3. The finite 
element simulation and analysis of results for the prototype is given in section 4, together with the analysis of the motor saturation. Section 5 contains the conclusions.

\section{Influence of polar arcs in VRM design}

The selection for the stator and rotor pole arcs are chosen to ensure self-starting of the machine and for shaping the torque profile. The minimum value of the polar arcs depends on the motor topology, and can be calculated by equation (1), presented in Section 3. The difference between the values of stator and rotor pole arcs directly influences the operation of the machine, the inductance profile and drive. Many of the practical designs have rotor pole arc slightly greater or almost equal to stator pole arc in VRMs [2].

Positive torque production in a VRM happens in the inductance growth interval, so the inductance is maximum when the current must be extinguished to not have the negative torque production. The ideal position for the current turn-off is the position of maximum inductance, but if stator and rotor pole arcs are equal is practically impossible to remove the current in the exact position, so a negative torque is produced until the current is completely extinct, as shown in Fig. 3, which decreases the average value of the torque. The solution to this is to remove the current before the peak of the inductance, which also decreases the average value of the torque once the maximum current remained for a smaller range.

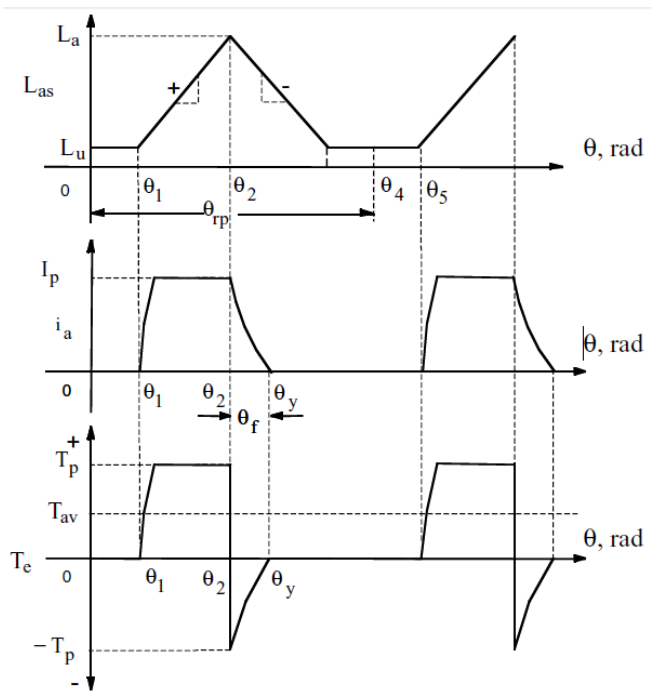

Fig. 3. Effect of equal stator and rotor pole arcs on torque generation. [2]

If the rotor polar arc is greater than the stator pole arc, the inductance remains a time at his maximum value until start the process of decreasing and misalignment of the poles. This region is known as dead zone, where no torque is produced even when there is current.

The advantage of having the motor operating in this manner is that one can start the current in the dead zone of minimum inductance and current extinction in the dead zone of maximum inductance, so during the growth period of the inductance the current is maximum and also the torque output, this will increase the average torque.

Figure 4 shows the situations described above, the influence of the polar arcs of the rotor and the stator in the motor inductance profile and production of torque as well as the characteristics of the drive current.
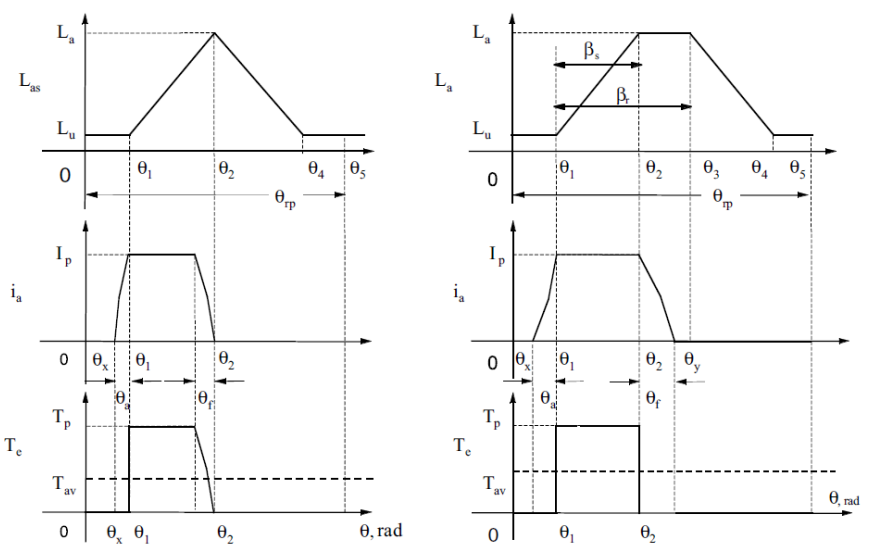

Fig. 4. Effect of pole arcs on torque generation for same peak currents. (a) $\beta r=\beta s$; (b) $\beta r>\beta s$. [2]

Therefore, it is very advantageous to have the rotor polar arc greater than the stator polar arc, in addition it can avoid the production of negative torque, facilitate the activation and increase the average value of the torque, elimination of negative torque reduces the ripple and hence the audible noise generation.

It is recommended that the polar arc of the rotor relative to the stator polar arc should be limited to the range of 0.85 to 1.2 , thus there is a variation of only $15 \%$ in the value of the aligned inductance [2]. The prototype developed in this work has the rotor polar arc $6 \%$ higher than the stator polar arc, following the established restriction.

\section{Design Procedures}

In general, the machine designs usually begins from the output quantity (such as the output power) desired for the system. Thus, this principle will be used in the motor designed here.

Fig. 5 shows the dimensions that have to be calculated for a single-phase VRM design.

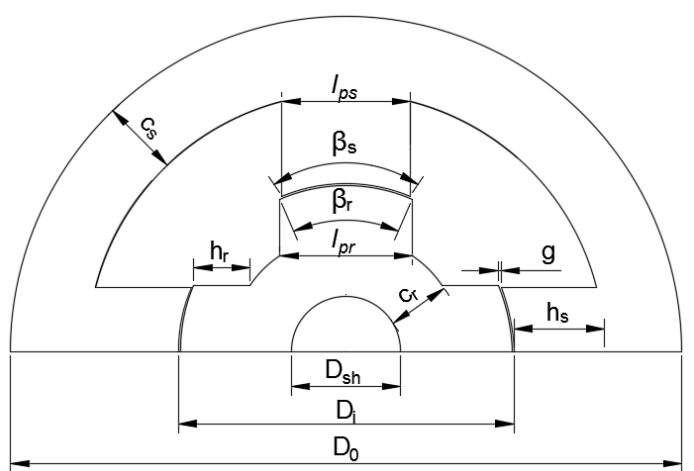

Fig. 5. Dimensions in a single-phase VRM.

In Fig. 5:

$\beta_{s}=$ stator pole arc;

$\beta_{r}=$ rotor pole arc;

$l_{p s}=$ stator pole width;

$l_{p r}=$ rotor pole width;

$c_{s}=$ stator back iron thickness;

$c_{r}=$ rotor back iron thickness; 
$h_{s}=$ stator pole height;

$h_{r}=$ rotor pole height;

$D_{s h}=$ rotor shaft diameter;

$D i=$ stator inner diameter;

$D_{0}=$ stator outer diameter;

$g=$ air gap.

To start the calculations, it is necessary to set some guidelines, such as the number of poles of the rotor and stator, the number of phases, the power output, rated speed, rated current and the magnetic material to be used in the construction of the stator and rotor.

The dimensioning presented below is for a single-phase variable reluctance motor, 4:4, and all coils energized simultaneously.

\section{A. Determination of dimensions}

The minimum value for the stator and rotor pole arc is given by [2]:

$$
\min \left(\beta_{s}, \beta_{r}\right)=\frac{4 \pi}{N_{s} N_{r}}
$$

Where:

$$
\begin{aligned}
& N_{s}=\text { number of stator poles; } \\
& N_{r}=\text { number of rotor poles. }
\end{aligned}
$$

The rotor pole arc must be greater or equal to the stator, and the ratio was recommended in Section 2.

The output equation for VRMs is given by:

$$
P_{d}=k_{e} k_{d} k_{1} k_{2} B A_{s} D_{i}^{2} L N_{r t}
$$

Where:

$$
\begin{aligned}
& P_{d}=\text { power output; } \\
& k_{e}=\text { efficiency; } \\
& k_{d}=\frac{\beta_{S} N_{r}}{2 \pi}=\text { duty cycle; } \\
& k_{1}=\frac{\pi^{2}}{120} \\
& 0.65 \leq k_{2} \leq 0.75 ; \\
& B=\text { flux density; } \\
& 25000 \leq A_{s} \leq 90000=\text { specific electric loading; } \\
& L=\text { stator core length; } \\
& N_{r t}=\text { rotor speed; }
\end{aligned}
$$

Torque can be obtained from equation (3) and by definition of $k_{l}$ and can be expressed by:

$$
T=k_{e} k_{d} k_{2} \frac{\pi}{4} B A_{s} D_{i}^{2} L
$$

From equation (2) $D_{i}$ can be calculated and so the other dimensions shown in Fig. 5. The stator inner diameter is used to estimate the value of the outer diameter, $D_{i}$ is a value between 0.4 to 0.7 times the $D_{0}$. The other dimensions are calculated as follows:

$$
\begin{aligned}
& D_{0}=\frac{D_{i}}{k} \quad(0.4 \leq k \leq 0.7) ; \\
& L=k D_{i} \quad(0.25 \leq k \leq 0.7) ; \\
& l_{p s}=D_{i} \operatorname{sen}\left(\frac{\beta_{s}}{2}\right) ; \\
& l_{p r}=D_{i} \operatorname{sen}\left(\frac{\beta_{r}}{2}\right) ; \\
& l_{p s}>c_{s} \geq 0.5 l_{p s}
\end{aligned}
$$

$$
\begin{aligned}
& 0.5 l_{p s}<c_{r}<0.75 l_{p s} ; \\
& h_{s}=\frac{D_{0}-\left(D_{i}+2 c_{s}\right)}{2} ; \\
& h_{r}=\frac{D_{i}-2 g-D_{s h}-2 c_{r}}{2} .
\end{aligned}
$$

The dimensioning of the coils is done in two stages, first is calculated the number of turns of each coil and after the conductor of the coil is determined. As shown by [3]:

$$
\begin{aligned}
& \mathrm{NT}=\frac{2 \cdot g}{I_{p}} \cdot \frac{B}{\mu_{0}} \\
& a_{c}=\frac{I_{p}}{J_{c} \sqrt{\frac{N_{S}}{2}}}
\end{aligned}
$$

Where:

$$
\begin{aligned}
& N T=\text { number of turns; } \\
& I_{p}=\text { peak current; } \\
& \mu_{0}=4 \pi \cdot 10^{-7}=\text { vacuum permeability; } \\
& a_{c}=\text { cross section area of the conductor; } \\
& J_{c}=\text { current density. }
\end{aligned}
$$

\section{B. Prototype development}

The prototype was dimensioned with the aim to replace a single-phase induction motor with a permanent capacitor, so the VRM designed must deliver the same conditions required by the load. Table 1 shows the electrical characteristics of the induction motor.

Table 1 - Electrical data of the induction motor.

\begin{tabular}{|l|c|}
\hline \multicolumn{1}{|c|}{ PARAMETER } & VALUE \\
\hline Input power (W) & 184 \\
\hline Rated speed (rpm) & 1700 \\
\hline Rated current (A) & 3.2 \\
\hline Rated voltage (V) & 220 \\
\hline Efficiency & 0.55 \\
\hline Power factor & 0.93 \\
\hline Number of poles & 4 \\
\hline Output power (W) & 94.1 \\
\hline Rated torque (N.m) & 0.5287 \\
\hline
\end{tabular}

Table 2 shows guidelines for the beginning dimensioning of VRM.

Table 2: Preliminary features of VRM.

\begin{tabular}{|l|c|}
\hline \multicolumn{1}{|c|}{ PARAMETER } & VALUE \\
\hline $\mathrm{N}_{\mathrm{s}}$ & 4 \\
\hline $\mathrm{N}_{\mathrm{r}}$ & 4 \\
\hline Input power (W) & 125 \\
\hline Rated speed (rpm) & 1700 \\
\hline Rated current (A) & 3.0 \\
\hline Peak current (A) & 9.0 \\
\hline Torque (N.m) & 0.7022 \\
\hline Air gap (mm) & 0.25 \\
\hline Core material & M19 \\
\hline Flux density (T) & 1.75 \\
\hline
\end{tabular}

First, it is calculated from equation (2) the value of the inner diameter, and from it is calculate other dimensions. 
It was adopted a higher value than calculated, as a safety margin.

Table 3 shows the dimensions calculated for the motor and Figure 6 the rotor blades and stator with some dimensions.

Table 3: Motor details.

\begin{tabular}{|l|c|c|}
\hline \multicolumn{1}{|c|}{ PARAMETER } & UNITS & VALUE \\
\hline$\beta_{s}$ & degrees & 45 \\
\hline$\beta_{r}$ & degrees & 47.725 \\
\hline$D_{i}$ & $\mathrm{~mm}$ & 55.5 \\
\hline$D_{0}$ & $\mathrm{~mm}$ & 111.00 \\
\hline$L$ & $\mathrm{~mm}$ & 38.85 \\
\hline$l_{p s}$ & $\mathrm{~mm}$ & 21.24 \\
\hline$l_{p r}$ & $\mathrm{~mm}$ & 22.25 \\
\hline$c_{s}$ & $\mathrm{~mm}$ & 12.75 \\
\hline$c_{r}$ & $\mathrm{~mm}$ & 12.75 \\
\hline$h_{s}$ & $\mathrm{~mm}$ & 15.01 \\
\hline$h_{r}$ & $\mathrm{~mm}$ & 7.25 \\
\hline$D_{s h}$ & $\mathrm{~mm}$ & 15 \\
\hline$N T$ & $\mathrm{units}$ & 78 \\
\hline$a_{c}$ & $\mathrm{~mm}$ & 1.0348 \\
\hline
\end{tabular}
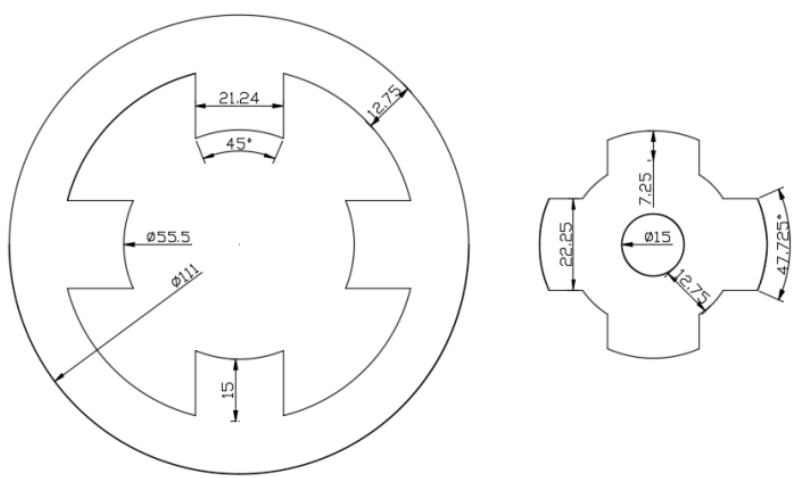

Fig. 6. Stator blades and the rotor of the designed VRM.

The determination of the conductor cross section is made by approximating the calculated area with the conductors manufactured, thus it is observed that the most appropriate conductor is 17 AWG copper conductor, with $1.04 \mathrm{~mm}^{2}$ cross section. Adopting a safety margin, the number of turns per phase used in the machine will be 90 turns. For the finite-element simulation, the coil should be represented by the area filled by conductors, so using a packing factor of 0.9 , the area filled by the coil is 104 $\mathrm{mm}^{2}$.

\section{Computer simulation}

The prototype will be examined in the light of the finite element method, from a computer simulation using the FEMM (Finite Element Method Magnetics), a complete and easy to use software which makes it possible to obtain numerous graphical and numerical results.

Parallel to FEMM the LuaEdit was used to program the motor simulation, programming from importing the dimensional drawing of the motor, made in AutoCad, up to the rotor movement and the achievement of results.

The computer simulation is performed in order to make a survey of inductance and torque profiles for different values of current and rotor position and thus determine the machine's saturation limit through the magnetization curve of the magnetic material and magnetic flux density plotted by FEMM.

Therefore, the examined current interval is $1.0 \mathrm{~A}$ to $15 \mathrm{~A}$, in $0.5 \mathrm{~A}$ intervals. For each current value the motor will develop a quarter of cycle, start from the misaligned position, pass through the aligned position and returns to the misaligned position in next quadrant, covering 90 degrees. This means that will be held 2610 simulations for each ratio of polar arcs, totalling 7830 simulations. So we can evaluate the torque behaviour during inductance growth and reduction.

Since the purpose of this work is to get the inductance profile of the designed prototype an ideal situation will be considered where the current applied is a square pulse that is extinguished immediately, in order not to have the negative torque production.

Next, will be presented results for different ratios of $\beta s$ and $\beta r$.

\section{A. $\quad \beta_{r}=\beta_{s}$}

Figures 7 and 8 show the three-dimensional curves of inductance versus current versus rotor position and twodimensional curve of torque versus rotor position for different currents and equal pole arcs.

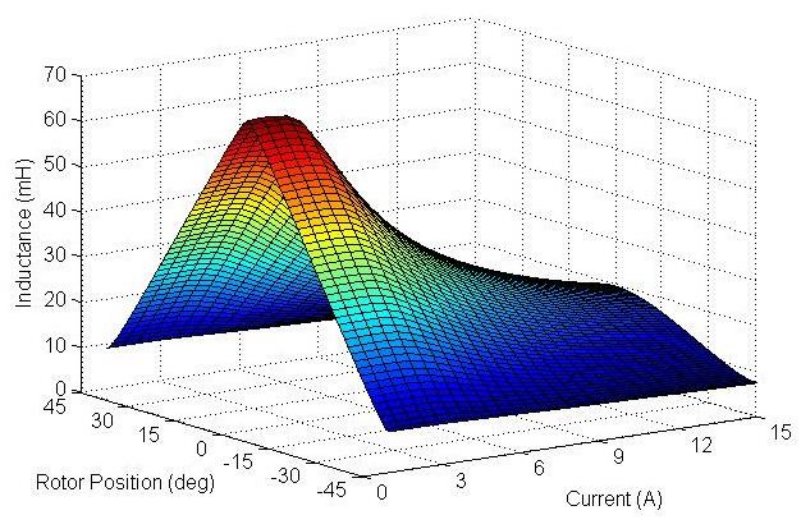

Fig. 7. Inductance profile.

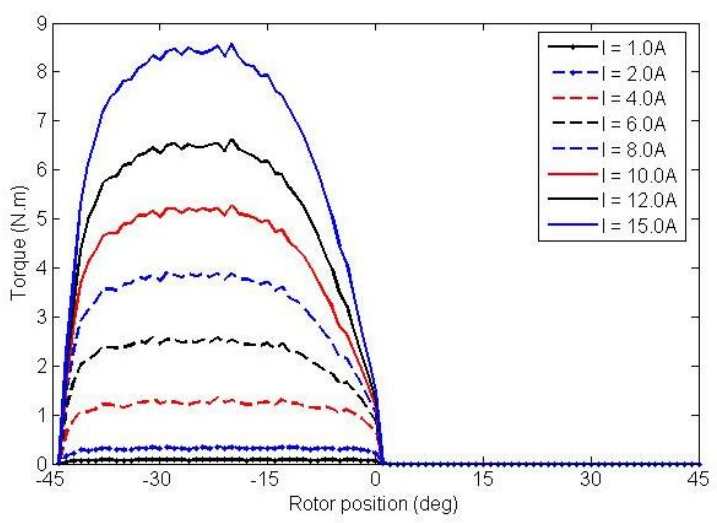

Fig. 8. Torque profile.

B. $\beta_{r}=1.06 \beta_{s}$

Figures 9 and 10 show the results for the $\beta_{r}$ value set in the prototype design, which is $1.06 \beta_{s}$. 


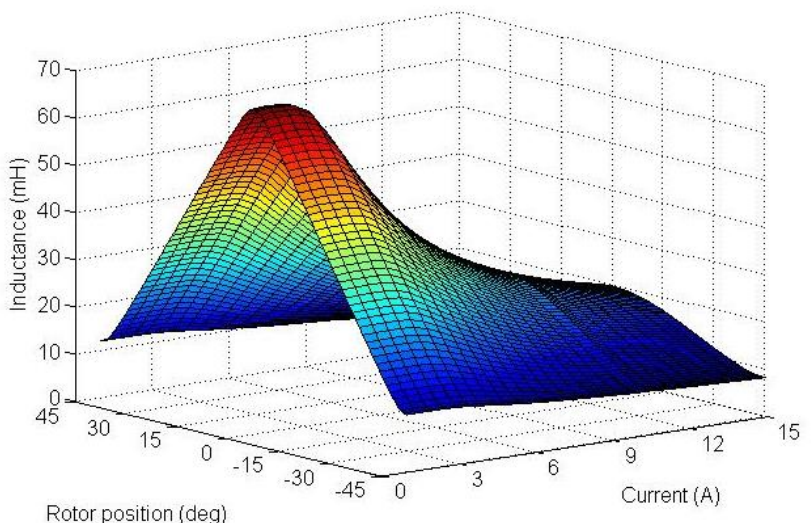

Fig. 9. Inductance profile.

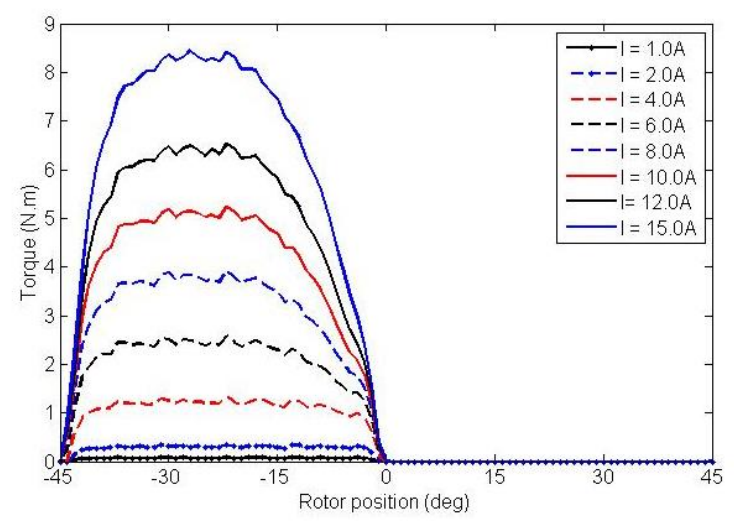

Fig. 10. Torque profile.

\section{C. $\beta_{r}=1.2 \beta_{s}$}

Figures 11 and 12 show the three-dimensional curves of inductance versus current versus rotor position and twodimensional curve of torque versus rotor position for different currents and for the upper limit recommended for $\beta_{r}$, which is $1.2 \beta_{s}$.

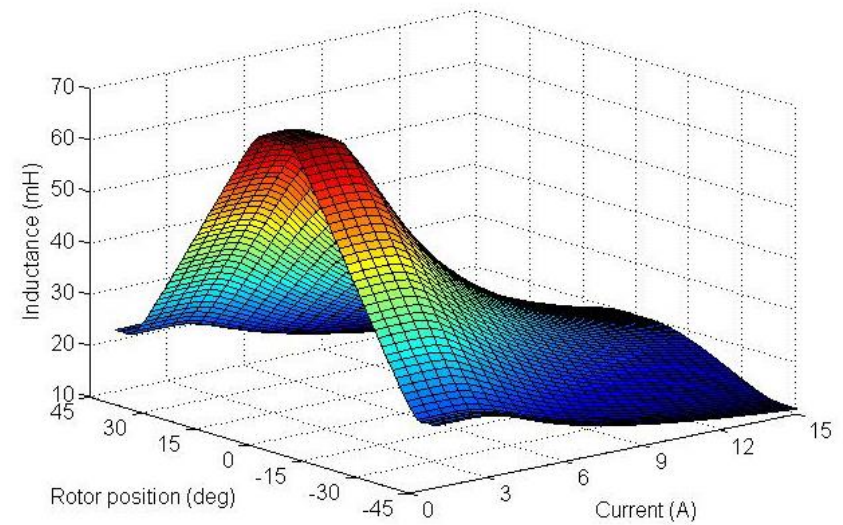

Fig. 11. Inductance profile.

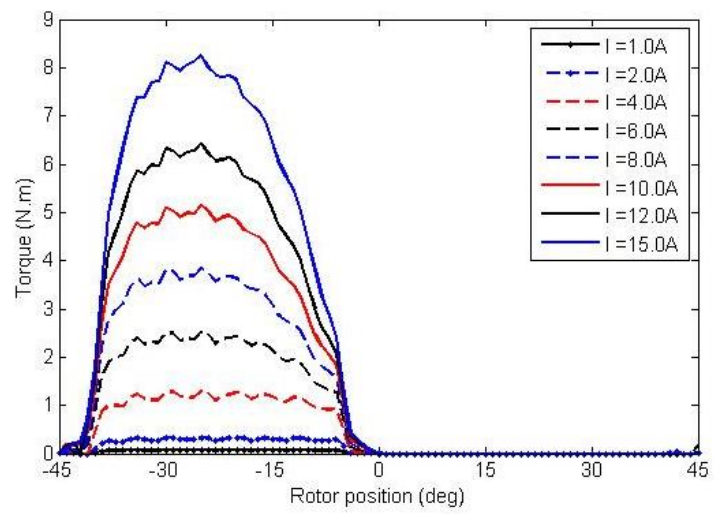

Fig. 12. Torque profile.

\section{Results Analysis}

Different polar arc ratios, $\beta_{\mathrm{s}}$ and $\beta_{\mathrm{r}}$, cause different pole widths, which increases the polar cross section overall area, leading to a decrease in the reluctance of the stator pole sections, allowing a greater flux to flow in the machine. This increases the torque while at the same time increases the phase inductance. What can be seen in Figure 13, which shows the inductance curve to different ratios of polar arcs, for the same value of current (3.0A).

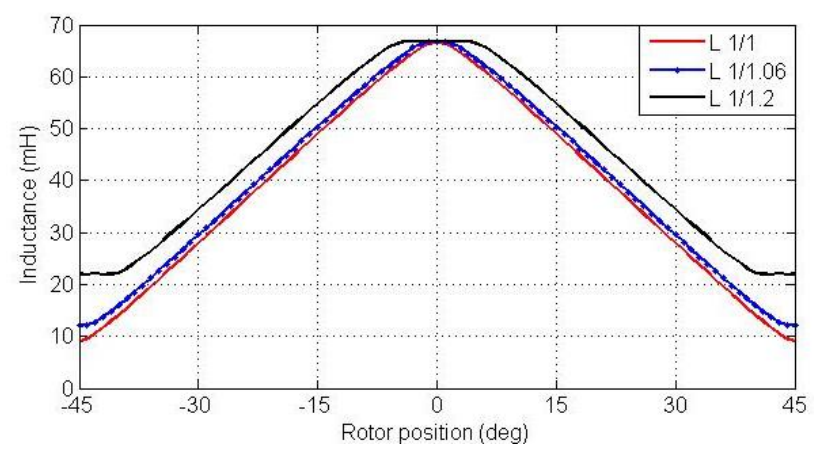

Fig. 13. Inductance profile for variation of rotor pole arc from 1 to 1.2 times the stator pole arc.

As shown in Figures 8, 10 and 12 the variation of the widths on the rotor poles has very little effect on torque shape characteristics, but having different pole arcs has the benefit of reducing the effects of commutation torque ripple to obtain an ideal and continuous torque as in other machines [2]. The demand on the torque-smoothing controller and hence on the current controllers is minimized by this torque shaping [2].

Observing the inductance and torque profiles presented in Section 4, it appears that for current values higher than $10 \mathrm{~A}$, the variation of inductance and torque is much lower, indicating saturation of the magnetic material and therefore a machine operating limit.

Figure 14 shows the flux density for aligned and misaligned positions of the prototype, Figure 15 shows the scale of colors for flux density B. Figure 16 shows the magnetization curve, $\mathrm{BxH}$, of the M19 steel used in rotor and stator blades. 


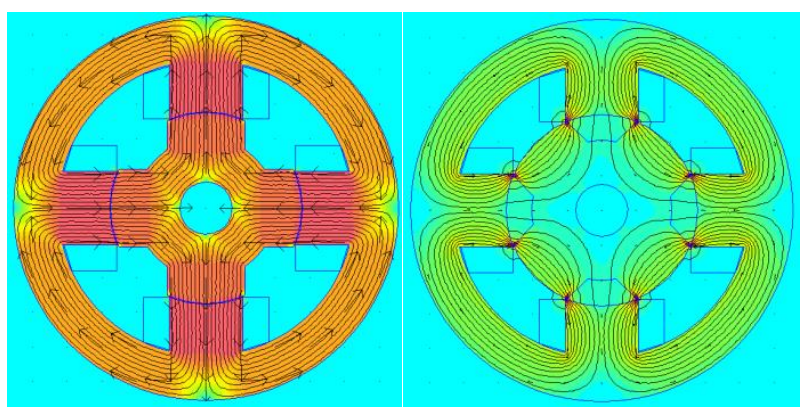

Fig. 14. Flux density for aligned and unaligned poles position.

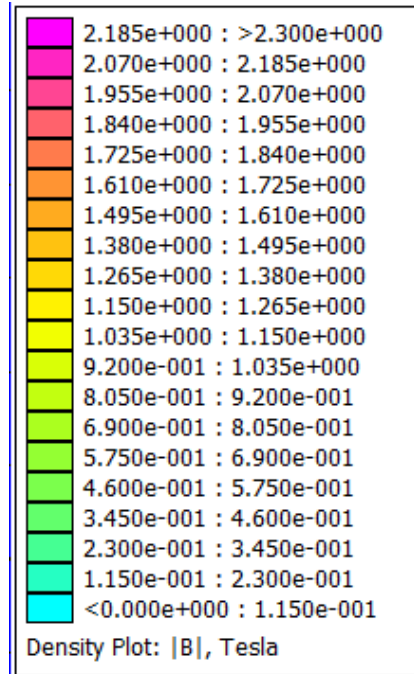

Fig. 15. Scale of colors for the flux density B.

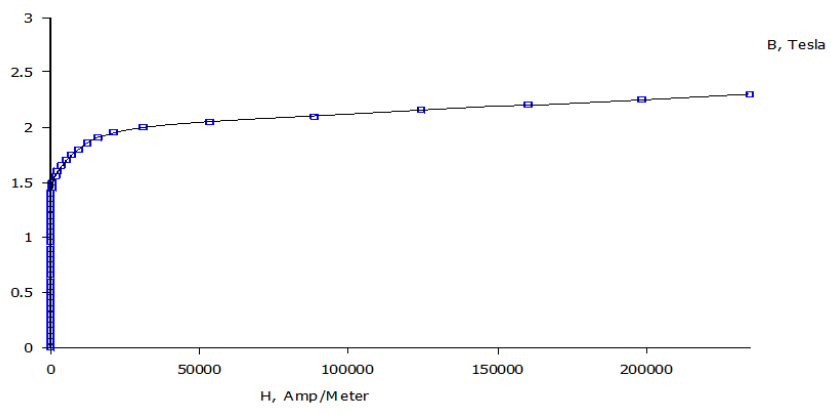

Fig. 16. Magnetisation or BxH curve of M19 steel.

After evaluating the data presented above it is concluded that the maximum peak current supported by the motor is $10 \mathrm{~A}$, limiting the peak current to that value we will have the motor operating on knee of the $\mathrm{BxH}$ curve. The operation on knee of the curve has two main advantages: optimal use of conductor current capacity and decrease of hysteresis losses due to non saturation of the magnetic material, with consequent efficient use of the volume of magnetic material that participates in defining the final cost of the machine. Thus, it contributes to increasing the machine efficiency and economic design.

Based on that value of current and base speed of $1700 \mathrm{rpm}$, the design calculation yields an output power of $346 \mathrm{~W}$, for an average torque 1.944 N.m.

\section{Conclusions}

The performance and features such as low production cost, robustness and reliability, presented by the variable reluctance motors are attractive to a wide range of size for many applications, whether industrial, automotive or residential.

The range and convenience of control that they allow, as fully reversible, provide very flexible torque/speed characteristics merely controlling the current and the switching angles, giving full 4-quadrant operation, without increasing the complexity of drives [4]. Indeed, all these features have contributed to the popularization of the use of the variable reluctance motors.

The ripple effect on torque and the difficulty of control, strong negatives points of VRM, can be reduced during the design phase from the in-depth study of the influence of the machine dimensions on its operation.

This paper is mainly intended to show the design procedures, a way to survey inductance and torque curves and the effects of polar arcs on forms of inductance and torque, directly influencing the operation and motor drive system. In recent times, efforts at current and hence torque control are becoming predominant over approaches using machine design [2]. A hybrid method of both pole shaping and torque control using modern techniques will enhance the VRM drive system performance to suit almost all high performance applications [2].

The results were obtained using a finite element simulation which was performed for various currents. This simulation allowed the evaluation of the machine magnetic saturation, and set an operational limit for the motor.

\section{Acknowledgement}

The author Ana Camila Ferreira Mamede is grateful to FAPEMIG (Fundação de Amparo à Pesquisa do Estado de Minas Gerais) and to CAPES (Coordenação de Aperfeiçoamento de Pessoal de Nível Superior) for the financial support for this research.

\section{References}

[1] Pyrhönen, J., Jokinen, T. and Hrabovcová, V. Design of rotating electrical machines. Wiley, Chichester (2008), U.K.

[2] Krishnan, R. Switched Reluctance Motor Drives. CRC Press, Boca Raton (2001).

[3] Min Thet, M. Design and Calculation of 75W Three-phase Linear Switched Reluctance Motor, in Proceedings Of World Academy Of Science, Motoring And Technology 2008, Vol. 36, pp. 108-113.

[4] Lawrenson, P., Stephenson, J., Blenkinsop, P., Corda, J., \& Fulton, N. Variable-speed switched reluctance motors, in IEE Proc., July 1980, Vol. 127, pp. 253-265.

[5] Miller, T. Switched reluctance motor and their control. Magna Physics Pub., Hillsboro (1993).

[6] Ahn, J. Switched Reluctance Motor. INTECH Open Access Publisher (2011).

[7] Radun, A. Design considerations for the switched reluctance motor, in IEE Transactions on Industry Applications, September/October 1995, Vol. 31, no. 5, pp. 1079-1087.

[8] Andrade, D., Costa, R., Teixeira, R. \& Fleury, A. Energy efficiency for fractional power loads, in IEEE Industry Applications Magazine, Nov/Dec 2006, Vol. 12, no. 6, pp. 1220. 